\title{
PERBANDINGAN ALGORITMA K-NEAREST NEIGHBOR, DECISION TREE, DAN NAIVE BAYES UNTUK MENENTUKAN KELAYAKAN PEMBERIAN KREDIT
}

\author{
Tupan Tri Muryono ${ }^{1}$, Ahmad Taufik ${ }^{2}$, Irwansyah ${ }^{3}$ \\ ${ }^{1,2}$ Sistem Informasi, ${ }^{3}$ Teknik Informatika \\ ${ }^{1,2,3}$ Sekolah Tinggi Manajemen Informatika dan Komputer (STMIK) Widuri Jakarta, Indonesia \\ Correspondence email: tupan_tm@yahoo.com
}

Article history: $\quad$ Submission date: Juni 14, $2021 \quad$ Revised date: Juni 28, $2021 \quad$ Accepted date: Juni 30, 2021

\begin{abstract}
The banking world in terms of providing credit to customers is a regular activity that has a large effect. In its application, non-performing loans or bad loans are often created due to poor credit analysis in the credit granting process, or from bad customers. The purpose of this study is to compare the results of algorithm accuracy between K-Nearest Neighbor (K-NN), Decision Tree, and Naive Bayes which results in the best accuracy will be implemented to determine creditworthiness. The attributes used in this study consisted of 11 attributes, namely marital status, number of dependents, age, last education, occupation, monthly income, home ownership, collateral, loan amount, length of loan and information as result attributes. The methods used in this research are $K$-Nearest Neighbor, Decision Tree, and Naive Bayes. From the results of evaluation and validation using k-5 fold that has been carried out using RapidMiner tools, the highest accuracy results from a comparison of 3 algorithms is using a decision tree (C4.5) of $98 \%$ in the 3 rd test.
\end{abstract}

Keywords: Credits, KNN, Dicision Tree, Nä̈ve Bayes

\begin{abstract}
ABSTRAK
Dunia perbankan dalam perihal pemberian kredit kepada nasabah merupakan aktivitas teratur yang memiliki efek besar. Dalam penerapannya, kredit yang bermasalah ataupun kredit macet kerap terjalin akibat analisis kredit kurang teliti dalam proses pemberian kredit, ataupun dari nasabah yang tidak baik. Tujuan dalam penelitian ini ialah untuk membandingkan hasil akurasi algoritma antara K-Nearest Neighbor (K-NN), Decision Tree, dan Naive Bayes yang mana hasil akurasi terbaiklah yang akan diimplementasikan untuk menentukan kelayakan pemberian kredit. Atribut yang digunakan dalam penelitian ini terdiri dari 11 atribut yaitu status perkawinan, jumlah tanggungan, usia, pendidikan terakhir, pekerjaan, penghasilan perbulan, kepemilikan rumah, jaminan, jumlah pinjaman, lama pinjaman dan keterangan sebagai atribut hasil. Metode yang digunakan dalam penelitian ini adalah K-Nearest Neighbor, Decision Tree, dan Naive Bayes. Dari hasil evaluasi dan validasi menggunakan k-5 fold yang telah dilakukan menggunakan tools RapidMiner diperoleh hasil akurasi tertinggi dari perbandingan 3 algoritma ialah menggunakan Decision Tree (C4.5) sebesar 98\% pada pengujian ke 3.
\end{abstract}

Kata Kunci: Kredit, KNN, Nä̈ve Bayes, Dicision Tree

\section{PENDAHULUAN}

Dunia perbankan dalam perihal pemberian kredit kepada nasabah merupakan aktivitas teratur yang memiliki efek besar. Dalam penerapannya, kredit yang bermasalah ataupun kredit macet kerap terjalin akibat analisis kredit kurang teliti dalam proses pemberian kredit, ataupun dari nasabah yang tidak baik (Turuis et al., 2017).

Kredit macet ataupun kredit bermasalah ialah sesuatu keadaan dimana pihak peminjam tidak sanggup melunasi pinjaman kepada pihak yang berikan pinjaman cocok waktu yang sudah didetetapkan (Mudrajad Kuncoro dan Suhardjono, 2002).
Agar menghindari terbentuknya kredit macet, seseorang analisis kredit perbankan wajib mengambil keputusan yang tepat untuk menerima maupun menolak pengajuan kredit. Buat mengenali kelayakan kredit di masa mendatang, dibutuhkan terdapatnya prediksi yang akurat, salah satunya memakai metode informasi mining. Informasi mining merupakan sesuatu sebutan yang digunakan buat menguraikan temuan pengetahuan di dalam database (Hanun \& Achmad Udin Zailani, 2020).

Informasi mining merupakan proses yang memakai metode statistik, matematika, kecerdasan buatan serta Machine Learning buat mengekstraksi serta mengenali data yang berguna serta pengetahuan yang terakit dari bermacam database besar (Han, J, Kamber, M, \& Pei, 2002). 
Dalam kaitannya informasi data mining mempunyai sebagian metode salah satunya merupakan metode klasifikasi. Klasifikasi merupakan pemrosesan buat menciptakan suatu model ataupun guna yang menarangkan serta menandai konsep ataupun kelas informasi, buat kepentingan tertentu. Klasifikasi data mining memiliki beberapa Algoritma diantaranya adalah $K$ Nearest Neighbor, Decision Tree, dan Naive Bayes (Budiyantara et al., 2020).

Tujuan dalam penelitian ini ialah untuk membandingkan hasil akurasi algoritma antara $K$ Nearest Neighbor, Decision Tree, dan Naive Bayes yang mana hasil akurasi terbaiklah yang akan diimplementasikan untuk menentukan kelayakan pemberian kredit.

Penulis ingin membandingkan hasil akurasi penelitian terdahulu menggunakan algoritma $K$ Nearest Neighbors (K-NN) yang ditulis oleh Tupan Tri Muryono dan Irwansyah dengan algoritma Decision Tree, dan Naive Bayes. Atribut dan jumlah data yang digunakan sama seperti penelitian yang terdahulu dengan topik implementasi data mining untuk menentukan kelayakan pemberian kredit dengan menggunakan algoritma K-Nearest Neighbors (K-NN). Berdasarkan penelitian yang dilakukan oleh peneliti, maka dapat disimpulkan, pada proses pengujian dengan menggunakan Algoritma K-Nearest Neighbors (K-NN) yang telah dilakukan menggunakan tools RapidMiner. Diperoleh hasil akurasi sebesar $93.33 \%$ pada pengujian ke 5 (Muryono \& Irwansyah, 2020).

Keterbaharuan dalam penelitian ini adalah algoritma yang digunakan ada tiga yaitu : $K$-Nearest Neighbor, Decision Tree, dan Naive Bayes sebagai perbandingan untuk menentukan kelayakan pemberian kredit. Diharapkan nantinya dapat mencegah terjadinya kredit macet yang dilakukan oleh nasabah.

\section{METODE PENELITIAN}

\section{Metode Pengumpulan Data}

Teknik pengumpulan data merupakan langkah yang paling strategis dalam penelitian karena tujuan utama dari penelitian adalah mendapatkan data. Untuk mendapatkan data yang diperlukan (Asrul Sani, 2018). Maka digunakan metode pengumpulan data yang digunakan adalah :

1. Observasi

Observasi merupakan metode pengumpulan data dengan melakukan pengamatan dan pencatatan secara teliti dan sistematis atas gejala-gejala atau fenomena yang sedang diteliti. Penulis malakukan pengamatan langsung pada PT. XYZ untuk mengidentifikasi masalah dan mengetahui bagaimana sistem yang berjalan di lembaga tersebut (Ade Davy Wiranata et al., 2020).

\section{Wawancara}

Wawancara merupakan teknik pengumpulan data yang dilakukan melalui tatap muka dan tanya jawab langsung antara peneliti dan narasumber. Seiring perkembangan teknologi, metode wawancara dapat pula dilakukan melalui mediamedia tertentu, misalnya telepon, email, atau skype. Penulis melakukan Tanya jawab langsung kepada pihak PT. XYZ. Dari hasil wawancara ini diharapkan dapat menambah kelengkapan data yang diperoleh dari hasil pengamatan (Galih Surono, 2020).

3. Dokumentasi

Dokumentasi adalah sebuah cara yang dilakukan untuk menyediaan dokumen-dokumen dengan menggunakan bukti yang akurat dari pencatatan sumber-sumber informasi khusus dari karangan/tulisan, wasiat, buku, undang-undang, dan sebagainya (Muryono et al., 2020).

Pada penelitian ini pengumpulan data melalui dokumen dilakukan dengan mempelajari fakta atau data yang ada pada file dokumentasi di PT. XYZ.

\section{Metode Penelitian Yang Digunakan}

Ada 3 metode yang digunakan pada penelitian ini yaitu K-Nearest Neighbor (K-NN), Decision Tree, dan Naive Bayes.

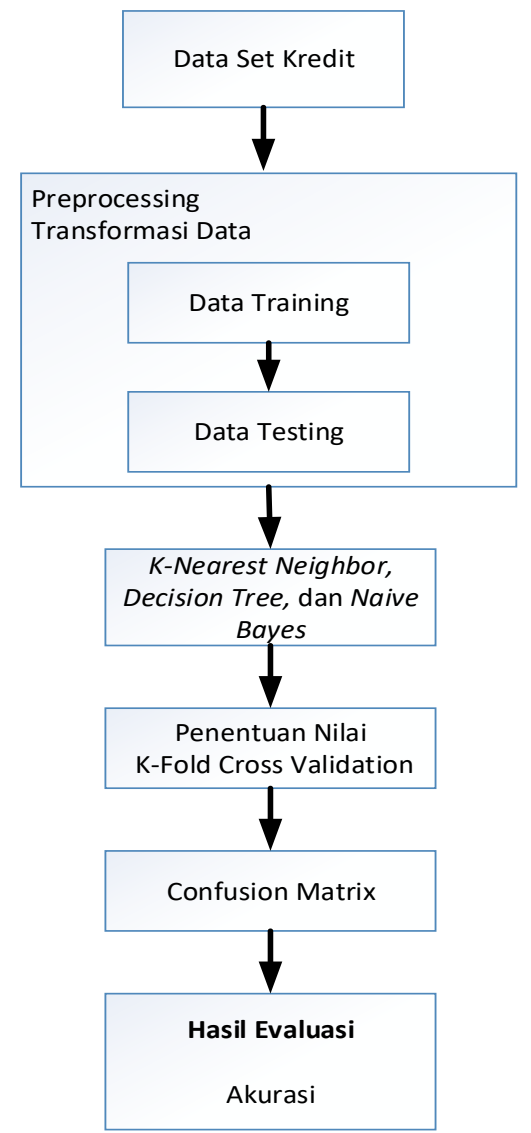

Sumber: (Tupan Tri Muryono et al., 2021)

Gambar 1. Langkah-Langkah Penelitian 
Pada penelitian ini data yang digunakan adalah dataset kredit yang didapatkan dari PT. XYZ sebanyak 500 data. Langkah selanjutnya dilakukan proses transformasi data set menjadi data training dan data testing. Langkah selanjutnya dataset diproses menggunakan algoritma K-Nearest Neighbor (K-NN), Decision Tree, dan Naive Bayes. Langkah selanjutnya menentukan nilai k-fold dalam penelitian ini menggunakan 5 kali proses pengujian. Langkah selanjutnya untuk menguji evaluasi dan validasi algoritma digunakan confusion matrix sehingga akan didapatkan nilai akurasi dari hasil eksperimen.

\section{HASIL DAN PEMBAHASAN}

\section{Pengolahan Data (Data Preparation)}

Pada tahapan ini dilakukan penyiapan data awal, pemilihan atribut atau variabal yang akan dianalisis, validasi variabel yang ada serta persiapan transformasi data. Adapun hal-hal yang dihasilkan pada fase persiapan data ini adalah :

Dilakukan persiapan data training sebanyak 350 data dan data testing sebanyak 150 data. Atribut yang digunakan terdiri dari 11 atribut yaitu : Status perkawinan, jumlah tanggungan, usia, pendidikan terakhir, pekerjaan, penghasilan perbulan, kepemilikan rumah, jaminan, jumlah pinjaman, lama pinjaman dan keterangan sebagai atribut hasil.

Berikut ini data atribut yang akan digunakan pada penelitian ini dapat kita lihat pada tabel 1 sebagai berikut :
Tabel 1. Atribut dan Nilai Dataset

\begin{tabular}{|c|c|c|}
\hline No & $\begin{array}{c}\text { Nama } \\
\text { Atribut }\end{array}$ & Nilai \\
\hline 1 & $\begin{array}{l}\text { Status } \\
\text { Perkawinan }\end{array}$ & $\begin{array}{l}\text { - Belum Menikah } \\
\text { - Sudah Menikah } \\
\text { - Janda/ Duda }\end{array}$ \\
\hline 2 & $\begin{array}{l}\text { Jumlah } \\
\text { Tanggungan }\end{array}$ & $\begin{array}{l}\text { - Tidak Ada } \\
-1 \text { orang } \\
-2-3 \text { orang } \\
->3 \text { orang }\end{array}$ \\
\hline 3 & Usia & $\begin{array}{l}-20-55 \\
-55-60\end{array}$ \\
\hline 4 & $\begin{array}{l}\text { Pendidikan } \\
\text { Terakhir }\end{array}$ & $\begin{array}{l}\text { - SD } \\
\text { - SLTP } \\
\text { - SLTA } \\
\text { - Diploma } \\
\text { - S1 } \\
\text { - >S1 }\end{array}$ \\
\hline 5 & Pekerjaan & $\begin{array}{l}\text { - Karyawan Swasta } \\
\text { - Pedagang } \\
\text { - PNS } \\
\text { - TNI/Polri } \\
\text { - Dosen }\end{array}$ \\
\hline 6 & $\begin{array}{l}\text { Penghasilan } \\
\text { Perbulan }\end{array}$ & $\begin{array}{ll}- & 1.000 .000-2.000 .000 \\
- & 2.000 .000-3.000 .000 \\
- & 3.000 .000-4.0000 .000 \\
- & >4.000 .000\end{array}$ \\
\hline 7 & $\begin{array}{l}\text { Kepemilikan } \\
\text { Rumah }\end{array}$ & $\begin{array}{ll}- & \text { Milik Sendiri } \\
- & \text { Sewa }\end{array}$ \\
\hline 8 & Jaminan & $\begin{array}{ll}\text { - } & \text { Sertifikat Tanah } \\
\text { - } & \text { Sertifikat Rumah } \\
\text { - } & \text { SK PNS/SK TNI-Polri } \\
\text { - } & \text { BPKB Kendraan Bermotor }\end{array}$ \\
\hline 9 & $\begin{array}{l}\text { Jumlah } \\
\text { Pinjaman }\end{array}$ & $\begin{array}{ll}- & 5.000 .000-15.000 .000 \\
- & 16.000 .000-30.000 .000 \\
- & 31.000 .000-50.000 .000 \\
- & 51.000 .000-100.000 .000 \\
- & >100.000 .000\end{array}$ \\
\hline 10 & $\begin{array}{l}\text { Lama } \\
\text { Pinjaman } \\
\text { (Bulan) }\end{array}$ & $\begin{array}{ll}- & 0-12 \text { Bulan } \\
- & 13-24 \text { Bulan } \\
- & 25-36 \text { Bulan } \\
- & 37-48 \text { Bulan } \\
- & >48 \text { Bulan }\end{array}$ \\
\hline 11 & Keterangan & $\begin{array}{ll}\text { - } & \text { Lancar } \\
\text { - } & \text { Macet } \\
\end{array}$ \\
\hline
\end{tabular}

Sumber: (Tupan Tri Muryono et al., 2021)

\section{Pengelompokkan Data}

Tabel 2. Contoh Sampel Data Testing

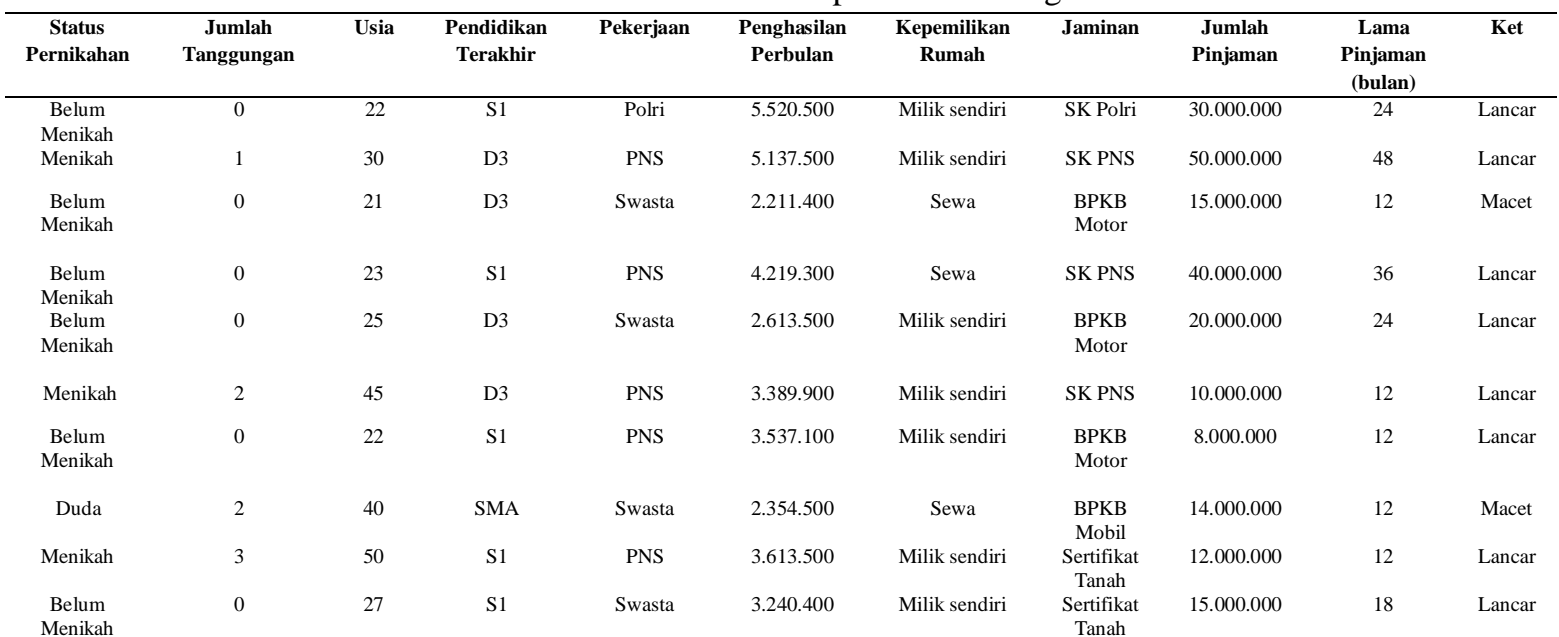

Sumber: (Tupan Tri Muryono et al., 2021) 
Pada tabel 2. diatas merupakan contoh 10 data yang digunakan untuk data latih atau data traning. Pada penelitian ini data training yang digunakan sebanyak 350 data nasabah.

\section{Evaluasi dan Validasi}

Evaluasi Model Menggunakan Tools RapidMiner. Desain model yang akan digunakan dapat kita lihat pada gambar 2,3,4, dan 5 sebagai berikut:

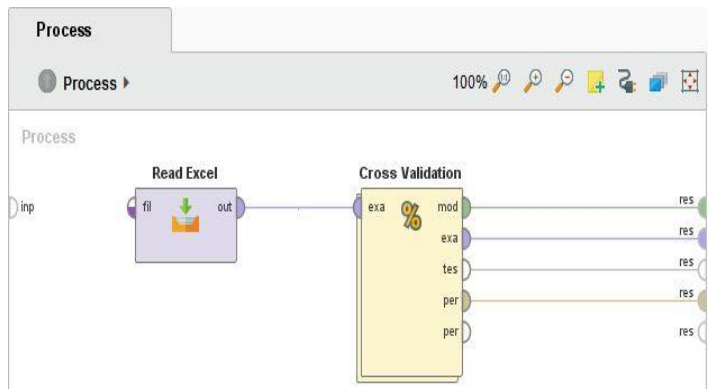

Sumber: (Tupan Tri Muryono et al., 2021)

Gambar 2. Proses Desain dan Import Data Dengan Tools RapidMiner

1. Read Excel : Operator ini dapat digunakan untuk memuat data dari spreadsheet Microsoft Excel.

2. Cross Validation: Operator yang bersarang. Ini memiliki dua subproses: subproses pelatihan dan subproses pengujian. Subproses pelatihan digunakan untuk melatih model. Model yang terlatih kemudian diterapkan dalam subproses pengujian. Kinerja model diukur selama fase Pengujian.

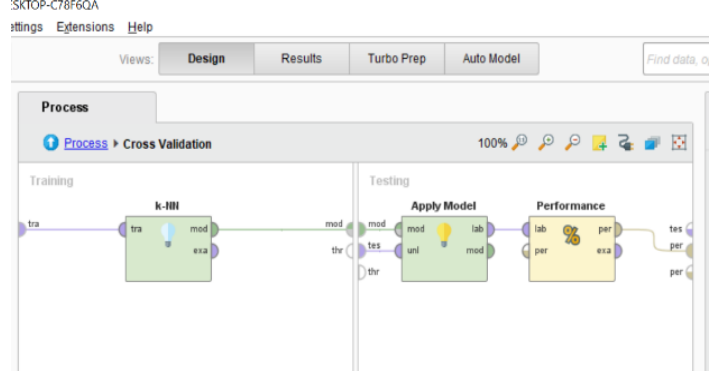

Sumber: (Tupan Tri Muryono et al., 2021)

Gambar 3. Model Validasi Algoritma K-NN

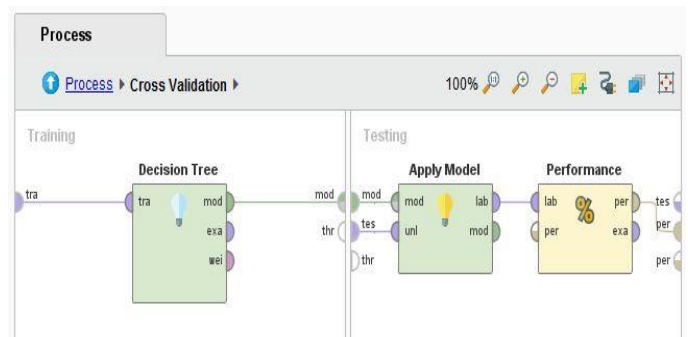

Sumber: (Tupan Tri Muryono et al., 2021) Gambar 4. Model Validasi Algoritma Decision Tree

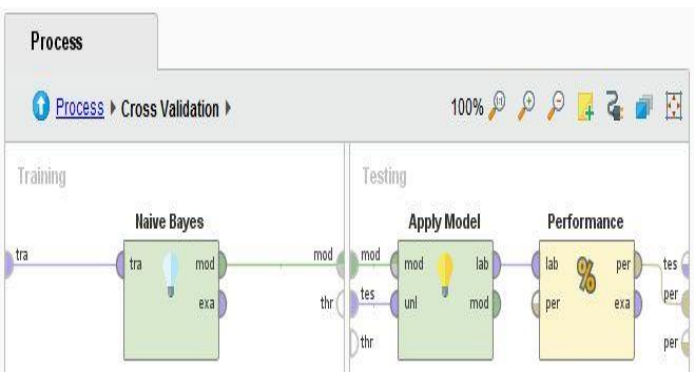

Sumber: (Tupan Tri Muryono et al., 2021)

Gambar 5. Model Validasi Algoritma Naïve Bayes

3. Model Validasi: Metode klasifikasi yang digunakan dalam penelitian ini yaitu $K$ Nearest Neighbor dapat dilihat pada gambar 3, Decision Tree dapat dilihat pada gambar 4, dan Naive Bayes dapat dilihat pada gambar 5.

4. Apply Model : Operator yang digunakan untuk penghubung metode $k$-Nearest Neighbor ke performance.

5. Performance : Operator yang digunakan untuk mengukur performance akurasi dari model.

Hasil Akurasi Tertinggi Evaluasi Model Menggunakan Cross Validation dan Confusion Matrix

1. Hasil Pengujian K-5 Cross Validation menggunakan algoritma K-NN

Penelitian ini melakukan proses evaluasi model dengan menggunakan k-5 cross validation. Dapat kita lihat pada gambar 6 sebagai berikut :

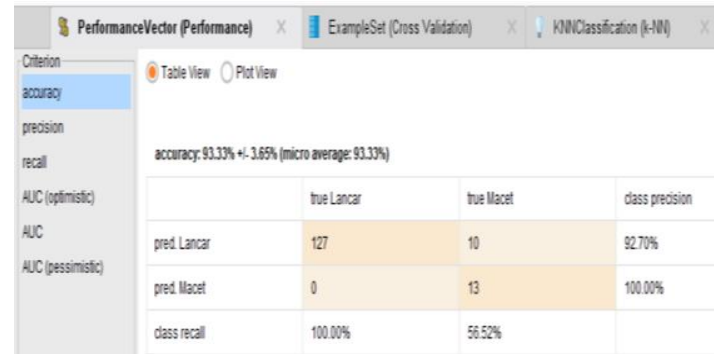

Sumber: (Tupan Tri Muryono et al., 2021) Gambar 6. Hasil Pengujian K-5 algoritma K-NN

Dari proses evaluasi model $K$-Nearest Neighbors dan proses validasi terbentuk hasil matrix Accuracy sebesar $93.33 \%$.

Dibawah ini merupakan perhitungan Akurasi menggunakan Confusion Matrix dari gambar 6 diatas.

Accuracy $=\frac{T P+T N}{T P+T N+F P+F N}+\frac{127+13}{127+13+0+10}+\frac{140}{150}=$ $0,9333=93,33 \%$ 
2. Hasil Pengujian K-3 Cross Validation menggunakan algoritma Decision Tree (C4.5)

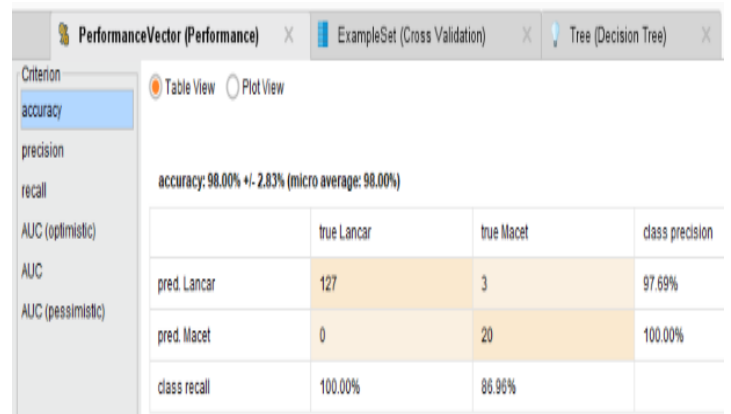

Sumber: (Tupan Tri Muryono et al., 2021)

Gambar 7. Hasil Pengujian K-3 Algoritma Decision Tree (C4.5)

Dari proses evaluasi model Decision Tree (C4.5) dan proses validasi terbentuk hasil matrix Accuracy sebesar $98.00 \%$.

Dibawah ini merupakan perhitungan Akurasi menggunakan Confusion Matrix dari gambar 7 diatas.

$$
\begin{array}{r}
\text { Accuracy }=\frac{T P+T N}{T P+T N+F P+F N}+\frac{127+20}{127+20+0+3}+\frac{147}{150}= \\
0,98=98,00 \% \ldots \ldots \ldots \ldots \ldots \ldots \ldots \ldots \ldots \ldots \ldots \ldots \ldots \ldots \ldots \ldots \ldots \ldots \ldots \ldots \ldots
\end{array}
$$

3. Hasil Pengujian K-3 Cross Validation menggunakan algoritma Nä̈ve Bayes

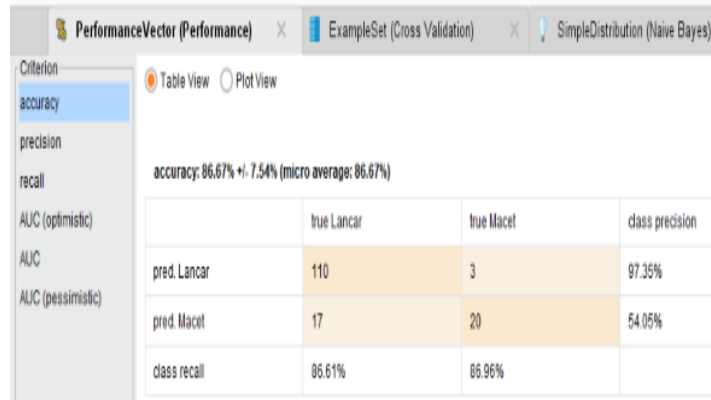

Sumber: (Tupan Tri Muryono et al., 2021)

Gambar 8. Hasil Pengujian K-3 Algoritma Nä̈ve Bayes

Dari proses evaluasi model Decision Tree (C4.5) dan proses validasi terbentuk hasil matrix Accuracy sebesar $86.67 \%$.

Dibawah ini merupakan perhitungan Akurasi menggunakan Confusion Matrix dari gambar 8 diatas.

$$
\begin{aligned}
\text { Accuracy }= & \frac{T P+T N}{T P+T N+F P+F N}+\frac{110+20}{110+20+17+3}+\frac{130}{150}= \\
& 0,8666=86,67 \% \ldots \ldots \ldots \ldots \ldots \ldots \ldots \ldots \ldots \ldots \ldots \ldots \ldots \ldots \ldots \ldots \ldots
\end{aligned}
$$

\section{Tabel Hasil Cross Validation 5 Fold}

Tabel 3. Hasil Pengujian Akurasi Cross Validation K 5 Fold

\begin{tabular}{lcccc}
\hline Metode & $\begin{array}{c}\text { K- } \\
\text { Fold 2 }\end{array}$ & $\begin{array}{c}\text { K- } \\
\text { Fold 3 }\end{array}$ & $\begin{array}{c}\text { K- } \\
\text { Fold 4 }\end{array}$ & $\begin{array}{c}\text { K- } \\
\text { Fold 5 }\end{array}$ \\
\hline K-NN & $84,67 \%$ & $82 \%$ & $90,67 \%$ & $93,33 \%$ \\
$\begin{array}{l}\text { Decision } \\
\text { Tree } \\
\text { (C4.5) }\end{array}$ & $90, \%$ & $98 \%$ & $94,70 \%$ & $96,66 \%$ \\
$\begin{array}{l}\text { Naïve } \\
\text { Bayes }\end{array}$ & $86 \%$ & $86,67 \%$ & $85,35 \%$ & $83,33 \%$ \\
\hline
\end{tabular}

Sumber: (Tupan Tri Muryono et al., 2021)

Hasil Pengujian Menggunakan K-5 Cross Validation

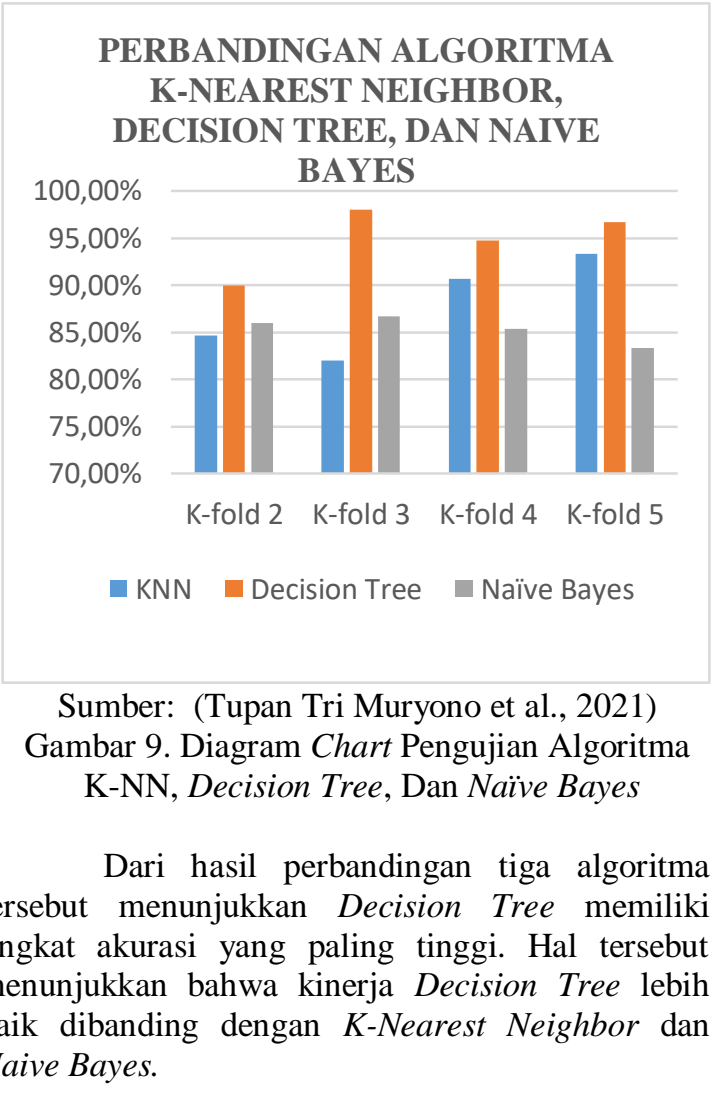




\section{KESIMPULAN}

Atribut yang digunakan untuk perbandingan tiga algoritma menentukan kelayakan pemberian kredit terdiri dari 11 atribut yaitu status perkawinan, jumlah tanggungan, usia, pendidikan terakhir, pekerjaan, penghasilan perbulan, kepemilikan rumah, jaminan, jumlah pinjaman, lama pinjaman dan keterangan sebagai atribut hasil. Dari hasil proses pengujian menggunakan tiga algoritma yang telah penulis lakukan menggunakan tools RapidMiner. Algoritma K-Nearest Neighbor (K-NN) memperoleh hasil akurasi tertinggi sebesar $93.33 \%$ pada pengujian ke 5. Algoritma Decision Tree (C4.5) memperoleh hasil akurasi tertinggi sebesar $98.00 \%$ pada pengujian ke 3. dan Algoritma Naïve Bayes memperoleh hasil akurasi tertinggi sebesar $86.67 \%$ pada pengujian ke 3 .

\section{DAFTAR PUSTAKA}

Ade Davy Wiranata, \& Irwansyah, Agus Budiyantara, A. S. (2020). Employee Candidate Selection Using the Saw and Topsis. 3(1), 22-35.

Asrul Sani. (2018). Penerapan Metode K-Means Clustering Pada Perusahaan. Jurnal Ilmiah Teknologi Informasi, 353, 1-7.

Budiyantara, A., Irwansyah, I., Prengki, E., Pratama, P. A., \& Wiliani, N. (2020). Komparasi Algoritma Decision Tree, Naive Bayes Dan K-Nearest Neighbor Untuk Memprediksi Mahasiswa Lulus Tepat Waktu. JITK (Jurnal Ilmu Pengetahuan Dan Teknologi Komputer), 5(2), 265-270. https://doi.org/10.33480/jitk.v5i2.1214
Galih Surono, N. N. P. (2020). Sistem Pendukung Keputusan Penentuan Siswa Teladan Menggunakan Metode Simple Additive Weighting (SAW) Studi Kasus : SD BHAKTI YKKP.Han, J, Kamber, M, \& Pei, J. (2002). Data Mining: Concept and Techniques (2nd ed.). Morgan Kaufmann.

Hanun, N. L., \& Achmad Udin Zailani. (2020). Penerapan Algoritma Klasifikasi Random Forest Untuk Penentuan Kelayakan Pemberian Kredit Di Koperasi Mitra Sejahtera. Infotech: Journal of Technology Information, 6(1), 7-14. https://doi.org/https://doi.org/10.37365/jti.v $6 i 1.61$

Mudrajad Kuncoro dan Suhardjono. (2002). Manajemen Perbankan: Teori dan Aplikasi (1st ed.). BPFE.

Muryono, T. T., \& Irwansyah. (2020). Implementasi data mining untuk menentukan kelayakan Pemberian kredit dengan menggunakan algoritma K-nearest neighbors. $\quad 6(1), \quad 43-48$. https://doi.org/https://doi.org/10.37365/jti.v $6 i 1.78$

Muryono, T. T., Irwansyah, I., \& Budiyantara, A. (2020). Penentuan Penerimaan Pegawai Menggunakan Metode Perbandingan Eksponensial (Mpe). Infotech: Journal of Technology Information, 6(2), 57-62. https://doi.org/10.37365/jti.v6i2.98

Tupan Tri Muryono, Ahmad Taufik, I. (2021). Perbandingan Algoritma K-Nearest Neighbor, Decision Tree, Dan Naive Bayes Untuk Menentukan Kelayakan Pemberian Kredit.

Turuis, T. F., Pangemanan, S. S., \& Affandi, D. (2017). Analisis Prosedur Pemberian Kredit Dengan Menggunakan Prinsip-Prinsip Good Corporate Governance Pada Pt. Bank Sulutgo. Jurnal Berkala Ilmiah Efisiensi, 17(01), 113-123. 